\title{
Explorations of PE Teaching Method Based on Human-oriented Philosophy
}

\author{
Jianling Li \\ Department of Physical Education, Xi'an International University, Xi'an, 710077, China
}

Keywords: Human-oriented; PE; Teaching; Thought

\begin{abstract}
The most important objective of PE course design lies in improving physical and psychological qualities of learners, further to let them to be more comprehensively developed. In view of constant promotion of China's quality-oriented education and continuously deepening of new curriculum reform, it has become a big trend to penetrate the human-oriented concept through PE teaching reform. Under the guidance of human-oriented philosophy, the PE teaching can promote the standardization and modernization of PE education. In this paper, it illustrates the basic connotations of human-oriented education, analyzes the prominent problems in PE teaching,and also put forward the PE teaching reform thought based on the human-oriented philosophy.
\end{abstract}

\section{Introduction}

Due to the constant progress of the current society's civilization, the human-oriented philosophy has already become one of most components of the current time values. The human-oriented concept is not merely an important promoting strength to realize the sustainable development. Meanwhile, the society's recognition of human-oriented concept has also expressed the civilization degree of the current society. During recent years, the Central Party and the State Council have positively advocated the concept of quality-oriented education. All educational institutions should advocate the concept of humanism, pay more attention to the physical and psychological health of learners, positively implement the PE teaching reform, further to implement the philosophy of modern education, promote students' learning enthusiasm to be consistently improved by innovative methods, further to cultivate high-quality talents with more comprehensive qualities and much healthier mind and body for the society.

\section{Basic Connotations of Human-oriented Educational Philosophy}

Human-oriented educational philosophy mainly refers to that, during the school's educational activities, it places the positive cultivation of learners' enthusiasm and initiative on the most important position. Moreover, on that basis, it can promote the development of learners' potential, further to realize the objective of full development and growth of learners' physical and psychological qualities. This educational concept needs related units to actually transform the situation that teachers were considered to be the teaching main bodies in the past, further to place the learners in the important position of teaching activities. During the overall classroom teaching, it must maintain much freer and more lively environment. On the basis of guaranteeing the healthy physical and psychological development of learners, it can actually let them to learn corresponding skills which can help themselves in the future. The key link of this educational philosophy is to show more respect for the own willing of learners, better motivate the learners' enthusiasm to participate in PE learning. In this way, it can form a good teaching context that teachers and students can frequently communicate and interact with each other. It is not only the necessity of the development of the current times, but also one absolute trend after the sustainable development of modern educational philosophy. To strengthen the human-oriented educational philosophy, it mainly includes respect for learners' individual wills, improvement of learners' dominant positions and clear understandings about learners' individual differences. It just requires the teaching activity advocating individualized quality education, pays more attention to the improvement of learners' comprehensive qualities, 
further to promote the better implementation of modern PE teaching conception under the guidance of humanism.

\section{Prominent Problems in Current PE Teaching}

Through observing the actual situations of current PE teaching in China, it mainly includes the following problems: quite single teaching method, quite outdated educational concept, quite backward teaching contents. Therefore, the traditional educational mode cannot only affect the learners' initiative to learn the PE course, but also make them not to actually devote themselves into PE teaching. Thus it is hard to more comprehensively develop the learners' mind and body. Meanwhile, in the long run, it emphasizes on improving learners' technologies within a short time, which must directly affect the cultivation of learners' lifelong PE educational view. Meanwhile, traditional PE teaching mode can only attach importance to the improvement of learners' physical skills. Such a quite limited teaching concept must result in the loss of learners' innovative concepts. Moreover, the emotional recognition is also insufficient, further to have impact on the comprehensive development of learners' qualities to a great extent. Moreover, due to the influence of traditional PE teaching, it results in the situation that a lot of PE educational activities pay more attention to the PE performance of learners and whether they achieve the standard. Such a concept of assessment absolutely will develop into one big factor restricting learners to actually master the values of PE learning. In view of that, only by fully implementing the human-oriented educational concept, carrying out reform through innovating concepts and educational methods, can it realize the objective of promoting comprehensive physical and psychological development of learners.

\section{Thought of PE Teaching Reform based on Human-oriented Philosophy}

\section{Actually Erecting the Human-oriented PE Teaching Concept}

In view of the actual situations in the past, the school's PE educators usually consider the sports competitions as the most important PE teaching method. Such a traditional PE teaching method only emphasizes on caring about learners' physiological function and increase of sports skills. The author thinks that, such a PE teaching mode came into being based on neglecting the objective individual differences of learners. The deficiencies lie in that, too mechanical competitions will cause great burdens for the physical and psychological health of learners. Thus, it will not only let learners to gradually loose enough interest in the classroom education of $\mathrm{PE}$, but also cause great damages to some individual bodies. In view of constant improvement of modern people's social civilization qualities, related PE educational items have been more and more exquisitely classified. Therefore, the human-oriented PE value has been greatly popularized and promoted. The PE teaching activity covering quite abundant human-oriented PE teaching activity has also put forward new requirements for the PE teachers. Consequently, it needs to better promote the full improvement of learners' qualities, further to cultivate the ability suitable for the current society and create the harmonious and natural PE educational environment.

\section{Positively Advocating the Concept of Happy PE}

To advocate the concept of happy PE, it requires PE teachers to actually keep the attitude of learning while teaching in the classroom teaching, offer help for students' learning and life with an equal and sincere attitude, further to obtain full trust and respect of learners. First of all, it needs to develop a happy learning objective. After communicating with learners, teachers should help them to develop the plans conforming to their own conditions and combined with the PE teaching. In addition, they should stimulate students to implement those plans with happy mood. Secondly, it should set up $\mathrm{PE}$ learning objectives with certain challenging difficulties. And then it can attract more students to positively take part in PE activities through stimulating students with good performance. Besides, the society and family should cooperate with each other more closely, further to carry out more 
comprehensive and popular propaganda of PE educational reform's method and significance, further to positively create the first-class environment that the social public take the initiative to join in sports. As a consequence, it can invisibly promote the cultivation of learners' PE consciousness and help them to actually erect the concept of happy PE.

\section{Improving the Contents and Methods of PE Teaching}

Firstly, it should provide a more democratic and easier PE learning environment for learners. High-qualified learning atmosphere can better stimulate their innovative capacities in learning, which is just an important task of the current PE teaching reform. The reform of PE teaching also needs an easy and free learning context, further to let students express their own opinions, better express themselves, learn and refer to each other in an easy and equal communicating progress, further to realize common development and progress. PE teachers should give full play to their function of positive guidance, fully encourage students to give play to their own talents, further to improve the entrepreneur and innovative capacities. Secondly, it needs to try to leave time for learners to make reflections and discussions during the teaching period. PE teachers cannot offer perfect teaching. As deficiencies exposed during the process, learners can raise their doubts by asking teachers questions. In this way, it cannot only improve the initiative of learners, but also help teachers to improve their own teaching level and adjust themselves to the teaching requirements under the new environment. It just proves that learners are the main bodies in learning. Teachers should lead the PE teaching and positively guide learners to devote themselves to PE teaching, learn to put forward problems and make reflections. Then learners can comprehensively exercise their ability to rise to the emergency, analyze problems and make innovations, further to lay a solid foundation for comprehensively improving the qualities of learners. Thirdly, it should stick to combination of theory and practice, positively encourage learners to make more practice. Teaching or learning of all courses cannot be separated from practice. It is not enough by merely relying on the theoretical knowledge. PE teaching needs more practice, further to strengthen all kinds of skills. The author thinks that, during the teaching process, $\mathrm{PE}$ teachers should not make evaluations on students too early, but positively guide them to make better self-improvement in practice.

\section{Making Psychological Hints to Stimulate Learners’ Emotions}

Demonstration actions of PE teachers play the role of offering psychological hints for learners. Actions demonstrated by PE teachers should try to be accurate with aesthetic beauty as much as possible. As a consequence, it can better improve the learners' learning enthusiasm, increase their confidence in better mastering sports movements. PE teachers should apply the learners' illusion and implement psychological hints, further to realize the objective of improving the training initiative of learners. For instance, while carrying out the $3 \times 400$ meters time running, teachers need to tell the correct time for the first time, which emphasizes on reminding learners to pay attention to the technological movements; while carrying out the second training, teachers need to tell the time less than 5 seconds consciously, further to let trainees think that such a progress is the result because of improved skills; while carrying out the third training, teachers can tell the time less than 10 seconds. In this way, although learners feel tired after running $3 \times 400$ meters, their running technologies are well improved, so are their performances. They can keep better emotions, who will not have bored emotions in the next training. During the classroom teaching, PE teachers can fully take advantage of unsound languages to implement psychological hints on learners, including eyesight, expression and gesture. To those learners with quite strong self-esteem, if PE teachers look at them with reproachful eyesight, it will be absolutely better than criticizing them by ordering their names. While inspecting whether learners master the concrete essential of movements, PE teachers should praise those students with good performance by admiring eyes, thus students can be encouraged. To those learners who cannot master essentials of movements within a short time, teachers should look at them with expected sight, further to improve their determination to bravely overcome difficulties and increase their initiative to devote themselves to training. 


\section{Improving Learners’ Enthusiasm of Independent Learning}

The learning interest and motivation are most directly embodied in the learning behavior. Therefore, it needs to emphasize on stimulating learners' interest and inner driving force during PE teaching. Only by actually improving the learners' interest and inner driving force, it can better lead learners to implement more independent and efficient PE learning activities. During the classroom teaching process, teachers should fully pay attention to the learners' changes of emotions, truly respect their characters and pass on the necessity of PE teaching to learners. Especially, PE activities can cultivate the good physical qualities of learners, all learners should actually understand that, further to stimulate learners' enthusiasm of PE learning. The cultivation of learners' enthusiasm of $\mathrm{PE}$ learning is an extremely important content, which can help learners to realize the full transformation, from passive and low-efficient learning to active and high-efficient learning method, namely to transform form being asked to learn to I want to learn. Meanwhile, PE teachers should also positively cultivate students, increase their responsibility of participation, stimulate their strong self-confidence, and also emphasize on implementing the improvement of learners' ability of activity, recognition and creation. PE teachers need to devote themselves to guiding learners to form good learning attitudes and habits, especially erect the consciousness of lifelong $\mathrm{PE}$, which has quite profound influence on the improvement of student's physical qualities.

\section{Creating a More Sound Evaluation Mechanism on PE Teaching}

Evaluation mechanism on PE teaching is an important content to fatherly guide the learners to implement PE learning. In view of constant promotion of new curriculum reform, the evaluation mechanism of PE learning should also try to be innovative as much as possible, further to completely transform the irrational evaluation mechanism in the traditional exam-oriented education in the past, so as to completely give up the evaluation form of only paying attention to results but neglecting the process. That evaluation method which totally attaches importance to the score excessively ignores the initiative of learners, the development of learning, thus it is bad for the improvement of the overall teaching ability. Therefore, during the PE teaching evaluation process, it should implement diversified evaluation form, positively create a comprehensive, objective and fair new evaluation mechanism, which means that it should insist on combination of quantitative evaluation and qualitative evaluation, further to comprehensively understand and evaluate the learning situations of learners. Of course, evaluations on learners should not only rely on the performance, more importantly, it should rely on the individual development in the future and progress, and also efforts they have made during this process and their improvement. In this way, it can actually stimulate their passion for PE learning, promote them to devote themselves to PE learning and truly form the concept of lifelong sports.

\section{References}

[1] Cong Peilin. Analysis on "Human-oriented" PE Teaching Quality-oriented Education in Colleges and Universities.Chinese \& Foreign Entrepreneurs, 2013(6).

[2] Li Shi. Exploration of Practicing "Human-oriented" Concept in PE Teaching of Colleges and Universities. Journal of TaiyuaN City Vocational College, 2013(8).

[3] Zhao Liang. Several Thoughts on Integrating the "Human-oriented” Concept into PE Teaching in Vocational Colleges.Heilongjiang Shizhi, 2013(11).

[4] Yang Yaoguang. PE Teaching Reform of Colleges and Universities under the Educational “Human-oriented” Concept. Contemporary Sports Technology, 2013(26).

[5] Wang Ning. Explorations of Fully Developing PE Teaching in Colleges and Universities under the "Human-oriented" Concept . Journal of Shandong Institute of Commerce and Technology, 2014(3). 
[6] Chang Yingchun. How to Realize "Human-oriented” Concept in PE Teaching of Colleges and Universities. Contemporary Sports Technology, 2014(23). 